\title{
Trends in Marine Turtle Strandings along the East Queensland, Australia Coast, between 1996 and 2013
}

\author{
Jaylene Flint,, ${ }^{1,2}$ Mark Flint,, ${ }^{1,3}$ Colin J. Limpus, ${ }^{1,4}$ and Paul C. Mills ${ }^{1}$ \\ ${ }^{1}$ Veterinary Marine Animals Research, Teaching and Investigation (Vet-MARTI) Unit, School of Veterinary Science, \\ The University of Queensland, Gatton, QLD 4343, Australia \\ ${ }^{2}$ The Florida Aquarium's Center for Conservation, Apollo Beach, FL 33572, USA \\ ${ }^{3}$ School of Forest Resources and Conservation, The Florida Aquarium's Center for Conservation, University of Florida, \\ Apollo Beach, FL 33572, USA \\ ${ }^{4}$ Queensland Department of Environment and Heritage Protection, Queensland Government, Brisbane, QLD 4102, Australia
}

Correspondence should be addressed to Jaylene Flint; jaylene.flint@uq.net.au

Received 29 July 2015; Revised 12 October 2015; Accepted 22 October 2015

Academic Editor: Nobuyuki Miyazaki

Copyright (C) 2015 Jaylene Flint et al. This is an open access article distributed under the Creative Commons Attribution License, which permits unrestricted use, distribution, and reproduction in any medium, provided the original work is properly cited.

\begin{abstract}
In-water monitoring of marine vertebrates is usually expensive while the use of stranding data can be used to provide a cost-effective estimation of disease and mortality. Strandings for Queensland are recorded in a web based database (StrandNet) managed by the Queensland Government's Department of Environment and Heritage Protection (EHP). Data recorded in StrandNet from the east coast of Queensland between 1996 and 2013 were investigated for patterns of stranding. Significant trends in Queensland over this time were (i) an increase in the number of animals reported stranded within this study site; (ii) a species (loggerhead and green marine turtles) prevalence; (iii) a seasonal effect on different age classes stranding with most overall strandings occurring between August and November; and (iv) stranding hotspots (Moreton Bay, Hervey Bay, Rockhampton region, and Cleveland Bays) persisting throughout the study timeframe. This study suggested that intervention strategies, such as rehabilitation, should be able to be focussed on periods of heightened importance and specific localities to minimize health risks and contribute to sustainable use of resources.
\end{abstract}

\section{Introduction}

All six species of marine turtles found within Australian waters are listed as species of conservation concern under the Environmental Protection and Biodiversity Conservation Act 1999 and in Queensland waters under the Queensland Nature Conservation Act 1992. Marine turtles are protected within a series of marine parks along the coastline as prescribed under the Marine Parks Act 2004 (Qld) and the Great Barrier Reef Marine Park Act 1975 (Commonwealth). Monitoring stranded marine turtles along the Queensland coast provides a measure of the effectiveness of these legislations and other temporary protection measures.

The monitoring of marine vertebrates, particularly marine turtles, in water can be expensive. Peltier et al. [1] assessed the quantitative significance of stranding events as an estimation of the fraction of cetacean carcasses that were drifting as opposed to those that washed ashore. They found that $57 \%$ and $87 \%$ of stranded common dolphins originated from within the $100 \mathrm{~m}$ and $500 \mathrm{~m}$ isobaths, respectively [1]. This suggested that stranding data may be used to identify trends and potential issues occurring in the near-shore environment but inferences about at-sea-deaths cannot be drawn.

Strandings can occur for a variety of reasons including ingestion of synthetic materials, vessel strike, coastal development, tourism, increased incidence of disease, incidental catch in shark control program gear, and incidental capture in recreational and commercial fisheries gear [2-5]. The identification of impact frequency and magnitude is necessary to assess potential consequences of human activities when developing management measures [6]. However, human impacts have a greater effect near shore $[4,6,7]$ potentially positively skewing prevalence of anthropogenic causes when assessing stranding data alone. 
It has been suggested that marine turtle stranding numbers follow seasonal trends influenced by weather events as well as land-based and at-sea seasonal activities. There have been links made between extreme weather and increased strandings [8-10].

This study investigated 18 years of marine turtle stranding data along the Queensland coast, compiled using the StrandNet database. The overall trend of strandings, sex, age class, and species distributions for season and known environmental impacts at selected locales were examined to interrogate the database for any variances in stranding that may elucidate factors involved in stranding events.

\section{Methods}

13854 turtles were reported stranded between 1996 and 2013 along the eastern Queensland coast. For each turtle a minimum of age, sex, species, fate of carcass, location, and time and cause of stranding was recorded.

2.1. Data. StrandNet is the Queensland Government's Department of Environment and Heritage Protection (EHP) statewide database which records dead, sick, and injured threatened marine animals for the entire coast of Queensland and adjacent Commonwealth waters. Records are received from members of the public and employees of EHP, Queensland Parks and Wildlife (QPWS), Queensland Department of Agriculture and Fisheries (DAF), and the Great Barrier Reef Marine Park Authority (GBRMPA). Information is collated and stored in this central database. Once reports are entered by on-ground staff the information available is verified by regional and state coordinators for standardisation.

2.2. Biometrics (Age, Sex, and Species). Standard measurements such as curved carapace length (CCL) and tail to carapace length (TCL) were collected [11].

Sex was determined by gonad examination by trained personnel either on site or using photographs or measurements $[12,13]$.

Species was determined as one of six turtle species including subspecies (green Chelonia mydas, loggerhead Caretta caretta, flatback Natator depressus, hawksbill Eretmochelys imbricata, leatherback Dermochelys coriacea, olive ridley Lepidochelys olivacea, and black turtle Chelonia mydas agassizi), as a hybrid animal or species unknown based on dichotomous key characteristics $[14,15]$.

2.3. Location. Study area encompassed latitude $-10.78^{\circ}$ to $-28.16^{\circ}$ and longitude $142.15^{\circ}$ to $155^{\circ}$ (Figure 1 ). The east coast of Queensland was selected as it has a long term and complete dataset with data collection biased to regions of survey and higher populations. This limitation is openly acknowledged by Meager and Limpus [10] but considered valid as a representative of a minimum recovery rate and indicative of trends occurring.

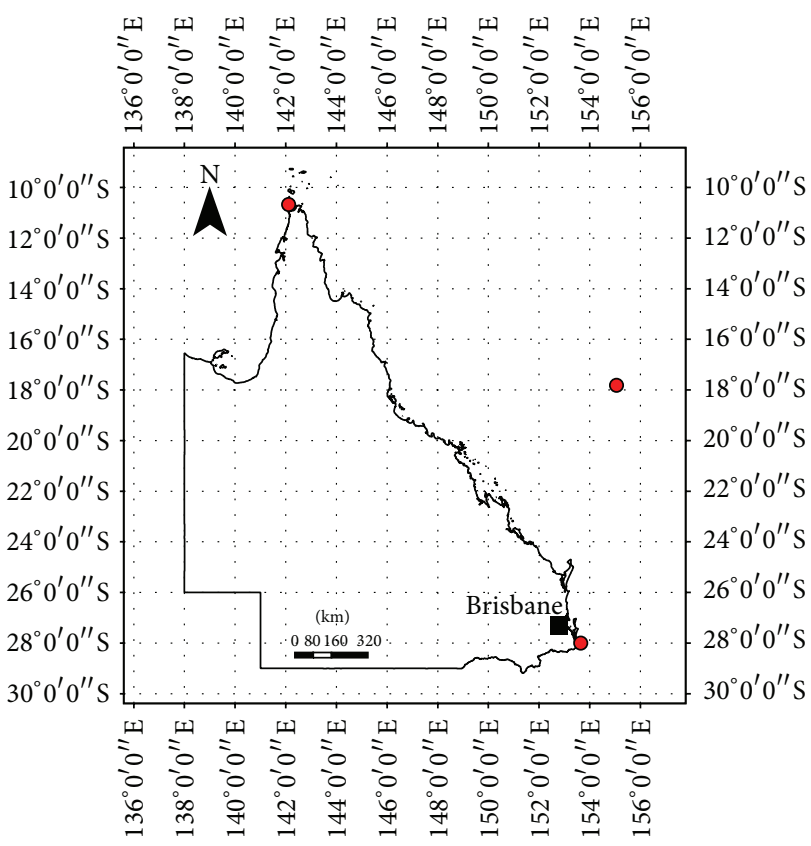

FIGURE 1: Map of Queensland coast showing the extents for which data was used. Red dots denote limits to study area.

2.4. Time. The date a turtle was reported stranded was used as a proxy of time of death providing month and season: Summer (December to February), Autumn (March to May), Winter (June to August), and Spring (September to November).

2.5. Cause of Stranding. The term "stranding" is used here to incorporate all reported sick, injured, incapacitated, or dead marine turtles that either were found ashore or, in rare cases, were encountered at sea. It included turtles which were entangled in fishing nets and synthetic debris or rescued from a situation where they would have died had it not been for human intervention [16].

Within StrandNet, the primary cause of death/stranding was identified based on gross examination, photograph, and/or necropsy by trained personnel. Cause of stranding identified in StrandNet was based on the summation of information available.

\subsection{Statistical Analyses}

2.6.1. Biometrics (Age, Sex, and Species). Animals were pooled into four age classes, as follows: small immature, large immature, adult sized, and unknown. Age class is only an approximation of maturity. It does not confirm reproductive development. The breakdown of age class for loggerheads was adapted from Limpus et al. [17] and hawksbills [18] and other species were adapted from Limpus et al. [11].

Animals were pooled based on gender as males, females, and unknowns. Unless an internal gonadal examination was conducted, animals were sexed based on TCL and CCL measurements. Sex determination was based on the ratio of these two measurements [11, 12, 17-19]. 
Gender did not exhibit sexual dimorphism for any age class, so subsequent analyses for sex were pooled.

2.6.2. Location. The latitude recorded in StrandNet was used to map the occurrence of strandings along the coast to identify the distribution and highlight potential "hotspots." As the exact location where a stranding was reported was not necessarily where the impact/incident occurred, strandings were grouped into latitudinal blocks of $0.5^{\circ}$ to account for this potential error.

2.6.3. Time. Boxplots were used to illustrate the number of turtles stranded per month across all years. This was done to illustrate potential seasonal trends.

Rates of strandings throughout the year were compared using chi-squared tests to determine variance between expected and observed rates for each species. Expected rates were defined to be equal distribution throughout the year for each group analysed.

The same test was applied to evaluate if there was a difference between the age classes of each species. It was expected that the total number of strandings would be evenly distributed throughout the year. Expected values were rounded up to the nearest whole number. All statistical analysis was performed using R [20].

In order to assess the seasonality of trends, the series was broken down into its three components, using the "decompose ()" function in R: trend, seasonal effect, and randomness. The series was seasonally adjusted by subtracting the estimated seasonal component from the original data. This data was then plotted to show the trend and the irregular components [21].

Autocorrelation function techniques were used to visually display potential seasonal patterns with the data.

2.6.4. Causes of Stranding and Mortality. The identified causes of "mortality" were grouped into six categories: unknown, natural, release, rehabilitation, anthropogenic, and depredation. Descriptive statistics were used to compare between season, year, age, and sex.

\section{Results}

A total of 13854 marine turtle strandings records from 1996 to 2013 were examined.

3.1. Biometrics (Age, Sex, and Species). Total number of strandings for each species and age class showed that the observed number was significantly different to the expected numbers of loggerhead small immature, loggerhead adult sized, loggerhead large immature, green large immature, and green adult sized, green small immature, and unknown species (Table 1).

More small immature green and unknown species were observed while fewer large immature green and loggerhead turtles stranded when comparing 1996 to 2013 (Table 2).

The most commonly reported stranded marine turtle species were green $(69.6 \%, 9641 / 13854,95 \%$ CI $0.69-0.70)$,
TABLE 1: Chi-squared total strandings by species and age class between years.

\begin{tabular}{lccc}
\hline Species and age class & $\chi^{2}$ & $\mathrm{df}$ & $P$ \\
\hline Loggerhead small immature & 64.47 & 17 & $<0.001$ \\
Loggerhead adult sized & 53.33 & 17 & $<0.001$ \\
Loggerhead large immature & 217.22 & 17 & $<0.001$ \\
Green large immature & 254.31 & 17 & $<0.001$ \\
Green adult sized & 514.29 & 17 & $<0.001$ \\
Green small immature & 2535.92 & 17 & $<0.001$ \\
Turtle small immature & 705.36 & 17 & $<0.001$ \\
Turtle large immature & 116.93 & 17 & $<0.001$ \\
Turtle adult sized & 481.22 & 17 & $<0.001$ \\
Hawksbill small immature & 227.21 & 17 & $<0.001$ \\
\hline
\end{tabular}

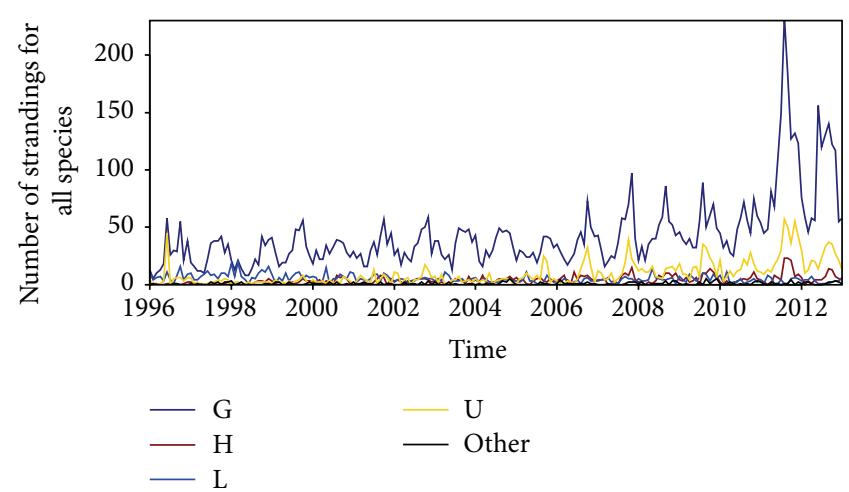

FIGURE 2: Total number of marine turtle strandings reported to StrandNet on the eastern Queensland coast for each species. G: Chelonia mydas. H: Eretmochelys imbricata. L: Caretta caretta. U: unidentified turtle. Other: Chelonia mydas agassizi, Dermochelys coriacea, Natator depressus, Lepidochelys olivacea, and Caretta caretta $\times$ Chelonia mydas hybrid.

loggerhead (7.8\%, 1081/13854, 95\% CI 0.07-0.08), hawksbill (5.9\%, 813/13854, 95\% CI 0.05-0.06), and then others (flatback, ridley, hybrids, black, and leatherback; 1.5\%, 201/13854, 95\% CI 0.01-0.02). In addition unidentified turtle species accounted for $15.3 \%$ (2118/13854, 95\% CI 0.15-0.16).

3.2. Location. The majority of strandings occurred in the $-27.0,-23.5$, and -19.0 latitudes, corresponding with coastal big cities and catchment outflows. Latitudes outside of these hotspots showed that there were peaks in different latitudes during different years. These peaks were of a smaller magnitude and not consistent.

3.3. Time. The number of strandings over time from 1996 to 2013 showed seasonal variation with peaks in October and troughs in March-June (Figures 2 and 3). Examination of data for green strandings shows that different age classes had different timing for peaks of strandings. Adults and large immature turtle strandings peaked in October while small immature turtle strandings peaked in August. The observed number of strandings for this species varied significantly throughout the year for all years with the exception of 2000 
TABLE 2: Distribution between age classes.

\begin{tabular}{|c|c|c|c|c|}
\hline Species & Age class & 1996 & 2013 & $R^{2}$ \\
\hline \multirow{4}{*}{ Green turtles } & Small immature & $21.8 \%(n=69)$ & $56.1 \%(n=494)$ & 0.7525 \\
\hline & Large immature & $32.3 \%(n=102)$ & $14.8 \%(n=128)$ & 0.6975 \\
\hline & Adult sized & $35.1 \%(n=111)$ & $25.7 \%(n=226)$ & 0.5147 \\
\hline & Unknown & $10.8 \%(n=34)$ & $3.6 \%(n=32)$ & 0.0329 \\
\hline \multirow{4}{*}{ Loggerhead turtles } & Small immature & $9.6 \%(n=8)$ & $23.3 \%(n=7)$ & 0.2874 \\
\hline & Large immature & $48.2 \%(n=40)$ & $30 \%(n=9)$ & 0.5856 \\
\hline & Adult sized & $31.3 \%(n=26)$ & $46.7 \%(n=14)$ & 0.166 \\
\hline & Unknown & $10.84 \%(n=9)$ & $0 \%(n=0)$ & $<0.001$ \\
\hline \multirow{4}{*}{ Unidentified turtles } & Small immature & $11.25 \%(n=13)$ & $23.08 \%(n=49)$ & 0.6132 \\
\hline & Large immature & $6.25 \%(n=5)$ & $4.62 \%(n=9)$ & 0.0922 \\
\hline & Adult sized & $16.25 \%(n=13)$ & $25.13 \%(n=49)$ & 0.0127 \\
\hline & Unknown & $66.25 \%(n=53)$ & $47.18 \%(n=92)$ & 0.1865 \\
\hline
\end{tabular}

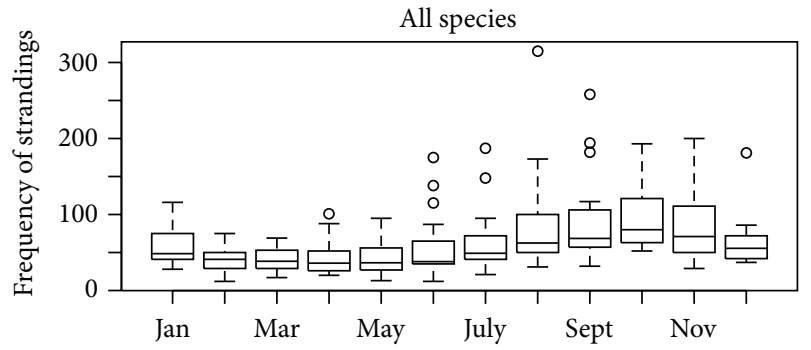

FIGURE 3: Boxplot of total monthly stranding values.

$\left(\chi^{2}=17.79\right.$, df $=11$, and $\left.\rho=0.0868\right)$. Loggerhead turtles showed some variance to this pattern with two cycles annually.

Observed (1st plot) stranding has a general upward trend (2nd plot) and a strong seasonal component (3rd plot) (Figure 4).

For all strandings the largest seasonal factor was October (28.82) and the lowest was March (-22.36), indicating peak in strandings in Spring and a trough in strandings in Autumn each year (Figure 4).

Autocorrelation techniques support the significant strong annual cycle to marine turtle strandings at the state level seen in Figure 4. It also highlighted certain latitudinal blocks (Cairns, Bowen/Proserpine Gladstone/Rockhampton, Hinchinbrook, Innisfail, and Sunshine Coast).

3.4. Cause. Natural causes contributing to mortality have varied since 1996. The proportion of anthropogenic and unknown causes of death has declined. The proportion of depredated animals and animals released on site has remained consistent. The number of animals sent to rehabilitation has increased over the years (Figure 5).

3.5. Species. The number of green turtles which have been reported stranded has increased from 1996 to 2011 but subsequently decreased (Figure 2). The proportion reported has remained consistent, with a small increase, ranging between 60 and $75 \%\left(R^{2}=0.0949\right)$.
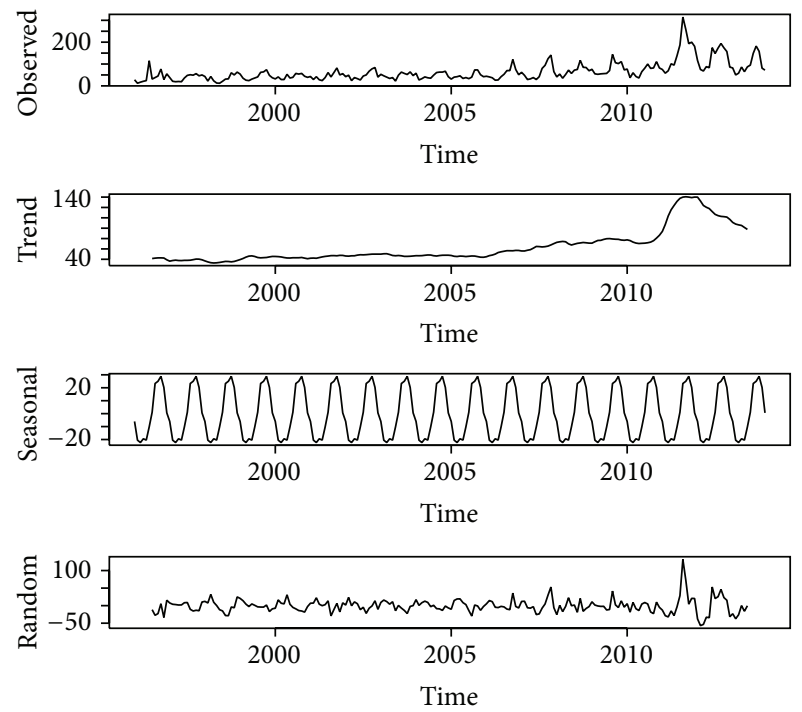

FIGURE 4: Decomposition of additive time series of total monthly strandings.

The number of loggerhead turtles which have been reported stranded has fluctuated since 1996 (Figure 2). There has been a decrease in the proportion of loggerheads that have stranded since $1996\left(R^{2}=0.7609\right)$.

The observed number of monthly turtle strandings between years showed a significant difference to the expected numbers of green strandings $\left(\chi^{2}=624.82\right.$, $\mathrm{df}=187$, and $\rho<0.001)$, loggerhead strandings $\left(\chi^{2}=278.72\right.$, $\mathrm{df}=187$, and $\rho<0.001)$, hawksbill $\left(\chi^{2}=228.39\right.$, $\mathrm{df}=187$, and $\rho<0.001)$, and unidentified turtles $\left(\chi^{2}=742.62\right.$, df $=187$, and $\rho<0.001)$.

Total number of observed strandings between years showed a significant difference to the expected numbers of green turtles $\left(\chi^{2}=2789.45\right.$, df $=17$, and $\left.\rho<0.001\right)$, hawksbill $\left(\chi^{2}=233.85, \mathrm{df}=17\right.$, and $\left.\rho<0.001\right)$, loggerhead $\left(\chi^{2}=156.43\right.$, df $=17$, and $\left.\rho<0.001\right)$, unidentified turtles $\left(\chi^{2}=1258.35\right.$, df $=17$, and $\left.\rho<0.001\right)$. 


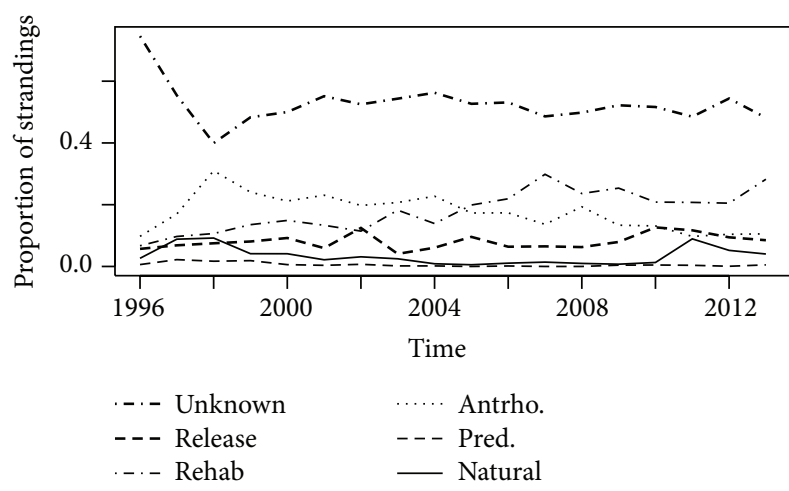

FIGURE 5: Proportion of turtles with an identified outcome.

\section{Discussion}

Overall this study found temporal, spatial, and age related patterns in the numbers of marine turtle strandings. Given these recurrent patterns, further investigation is warranted to develop models that predict the resultant increases in the numbers of strandings from each of these confounding factors to determine when to mitigate negative impacts.

This study shows years of elevated strandings for all age classes in marine turtles in general and specifically all age classes of green turtles and loggerhead turtles (Table 1).

Between 1996 and 2013 the most frequent species recorded as stranded were green and loggerhead $(n=10722$, $77 \%$ ); and of the 13854 turtles reported stranded on Queensland coastline, there was a prevalence of dead green turtles, irrespective of age class (69.6\%). Both of these species are common residents of Queensland waters, whereas the olive ridley, black, and leatherback have relatively lower population numbers within these waters [2, 19, 22-25] (Table 2).

The increase in the numbers of juvenile green turtles which strand over the 18-year study could be due to several issues including the increase or development of emerging age specific impediments and increase in the size of the population. This could be influenced by small immature turtles being immunologically naive and susceptible to environmental stressors. New diseases or the coastal and catchment urbanization and climate change that Queensland is experiencing may be impacting this least robust cohort of the population $[3,8,26]$.

When pooled for age classes there is a visible cyclical trend of strandings occurring through the year for all turtles, greens, hawksbills, and unknown species. This uneven distribution throughout the year indicates that there may be underlying confounding processes linked to season that is influencing the rate of stranding (Table 1). Time series analysis (Figures 2 and 4) showed that turtle stranding is cyclical across years with more turtles stranding during the months coming out of winter (August to November) and fewer turtles stranding in the months when waters start to cool (April to June). Further periods of unusual extreme weather may result in outliers in these normal seasonal patterns [8-10,27]. These outliers warrant independent investigation as they relate to periods of increased need for resources and rehabilitation if turtle deaths are to be minimized by intervention.

Strandings were distributed along the Queensland coast in localised "hotspots." These hotspots correspond to the semienclosed embayments of Moreton Bay, Hervey Bay, Rockhampton region, and Cleveland Bay. The hotspots are also in the vicinity of major catchments areas along the coast including the Brisbane, Fitzroy, Burnett, and Burdekin Rivers. This is important because it highlights where extra resources are required and brings in local areas which warrant further investigation.

The number of animals without an identified cause of death has remained at a high level since 1996. This could be due to the condition of the carcasses when they are found, inexperienced observers, or a lack of funds/resources to conduct adequate analysis. The identification of causes of mortality is an essential step involved in the understanding of the health of individuals and the long term health of the population [28] and, in turn, can be used as a sentinel of environmental health [29] and management priorities.

Through the years there has been an increase in the number of animals which have been sent to rehabilitation centres (Figure 5). This has correlated with a shown need and resultant increase in the number of centres which provide care. Despite this there has been no study conducted into the proportion of these animals which are released and survive or subsequently restrand. It is of particular interest to know the overall benefit of rehabilitation.

Anthropologic causes of death have decreased over the years which supports the hypothesis that current management actions such as go slow zones, TEDs, protection areas, and net attendance rules are successful as mitigation strategies (Figure 5). The other identified causes of stranding have remained at a low level.

Even though the number of dead turtles that strand is only an index on the actual number of animals which die in total $[1,30]$, monitoring stranding of marine turtles along the coastline provides a powerful first-line tool in gathering data to make management decisions. It is now imperative that this data be used to advance other tools such as modelling to accurately predict important habitats, patterns, needs, and resource allocation to mitigate marine turtle deaths. As marine turtles are facing the same threats globally, this strategy could be implemented elsewhere and used as a uniform stepwise approach to objectively assess coastline and rehabilitation centre management. Once implemented, success needs to be measured over medium to long term (10 years) trends and be treated as a dynamic plan that is adjusted as any issues are identified.

This study showed the lowest stranding rates that occurred in the large immature population of marine turtles in Queensland but all of the population is influenced by annual seasonal effects with stranding rates being exacerbated by extreme events.

\section{Disclosure}

This paper does not contain any studies with animals performed by any of the authors. 


\section{Conflict of Interests}

The authors declare that they have no conflict of interests.

\section{Acknowledgments}

The authors would like to thank the Queensland Marine Wildlife Strandings and Mortality network and all contributors to the StrandNet database. They would also like to thank turtle rehabilitation facilities staff at Underwater World-SEA LIFE (Mooloolaba, QLD), Australia Zoo (Beerwah, QLD), and SeaWorld (Gold Coast, QLD) for providing access to their data. This study was partially funded by the Australian Research Council Linkage Project Grant LP110100569.

\section{References}

[1] H. Peltier, W. Dabin, P. Daniel et al., "The significance of stranding data as indicators of cetacean populations at sea: modelling the drift of cetacean carcasses," Ecological Indicators, vol. 18, pp. 278-290, 2012.

[2] M. S. Section, Recovery Plan for Marine Turtles in Australia, Environment Australia, 2003.

[3] M. Flint, J. C. Patterson-Kane, C. J. Limpus, and P. C. Mills, "Health surveillance of stranded green turtles in Southern Queensland, Australia (2006-2009): an epidemiological analysis of causes of disease and mortality," EcoHealth, vol. 7, no. 1, pp. 135-145, 2010.

[4] J. Hazel, I. R. Lawler, and M. Hamann, "Diving at the shallow end: green turtle behaviour in near-shore foraging habitat," Journal of Experimental Marine Biology and Ecology, vol. 371, no. 1, pp. 84-92, 2009.

[5] National Research Council Committee on Sea Turtle Conservation, Decline of the Sea Turtles: Causes and Prevention, National Academies Press, Washington, DC, USA, 1990.

[6] K. Dobbs, Marine Turtles in the Great Barrier Reef World Heritage Area: A Compendium of Information and Basis for the Development of Policies and Strategies for the Conservation of Marine Turtles, Great Barrier Reef Marine Park Authority, 2001.

[7] J. Hazel and E. Gyuris, "Vessel-related mortality of sea turtles in Queensland, Australia," Wildlife Research, vol. 33, no. 2, pp. 149-154, 2006.

[8] M. Flint, P. A. Eden, C. J. Limpus, H. Owen, C. Gaus, and P. C. Mills, "Clinical and pathological findings in green turtles (Chelonia mydas) from gladstone, queensland: investigations of a stranding epidemic," EcoHealth, vol. 12, no. 2, pp. 298-309, 2015.

[9] H. Marsh and D. Kwan, "Temporal variability in the life history and reproductive biology of female dugongs in Torres Strait: the likely role of sea grass dieback," Continental Shelf Research, vol. 28, no. 16, pp. 2152-2159, 2008.

[10] J. J. Meager and C. J. Limpus, "Marine wildlife stranding and mortality database annual report 2011. III. Marine Turtle," The State of Queensland (Department of Environment and Heritage Protection), 2012.

[11] C. J. Limpus, P. J. Couper, and M. A. Read, The Green Turtle, Chelonia mydas, in Queensland: Population Structure in a Warm Temperature Feeding Area, vol. 35, Memoirs of the Queensland Museum, Brisbane, Australia, 1994.
[12] C. J. Limpus and D. J. Limpus, "Biology of the loggerhead turtle in western South Pacific Ocean foraging areas," in Loggerhead Sea Turtles, pp. 93-113, Smithsonian Institution, Washington, DC, USA, 2003.

[13] C. J. Limpus and P. C. Reed, "The green turtle, Chelonia mydas, in Queensland: a preliminary description of the population structure in a coral reef feeding groud," in Biology of Australasian Frogs and Reptiles, G. Grigg, R. Shine, and H. Ehmann, Eds., pp. 47-52, Surrey Beatty \& Sons, Sydney, Australia, 1985.

[14] Environmental Protection Agency, Indo-Pacific Marine Turtles Identification Guide, Environmental Protection Agency QPaWS, Brisbane, Australia, 2008.

[15] Great Barrier Reef Marine Park Authority, Great Barrier Reef Marine Turtles Identification Sheet, Great Barrier Reef Marine Park Authority, Townsville, Australia, 2007.

[16] J. R. Geraci and V. J. Lounsbury, Marine Mammals Ashore: A Field Guide for Strandings, National Aquarium, Baltimore, Md, USA, 2005.

[17] C. J. Limpus, P. J. Couper, and M. A. Read, "The loggerhead turtle, Caretta caretta, in Queensland: population structure in a warm temperate feeding area," in Memoirs of the Queensland Museum Brisbane, vol. 37, pp. 195-204, 1994.

[18] C. J. Limpus, “The hawksbill turtle, Eretmochelys imbricata, in Queensland: population structure within a southern Great Barrier Reef feeding ground," Wildlife Research, vol. 19, no. 4, pp. 489-506, 1992.

[19] C. J. Limpus, A Biological Review Of Australian Marine Turtles. 5. Flatback, Natator depressus, Environmental Protection Agency, Brisbane, Australia, 2007.

[20] R. Core Team, R: A Language and Environment for Statistical Computing, R Foundation for Statistical Computing, Vienna, Austria, 2014.

[21] A. Coghlan, A Little Book of R for Time Series, Wellcome Trust Sanger Institute, Cambridge, UK, 2014.

[22] C. J. Limpus, A Biological Review of Australian Marine Turtle Species, 4 Olive Ridley Turtle Lepidochelys olivacea (Eschscholtz), Environmental Protection Agency, Brisbane, Australia, 2008.

[23] C. J. Limpus, A Biological Review of Australian Marine Turtles. 1. Loggerhead Turtle, Caretta caretta, Environmental Protection Agency, Brisbane, Australia, 2008.

[24] C. J. Limpus, A Biological Review of Australian Marine Turtles. 2. Green Turtle, Chelonia mydas (Linnaeus), Environmental Protection Agency, Brisbane, Australia, 2008.

[25] C. J. Limpus, A Biological Review of Australian Marine Turtles. 6. Leatherback Turtle, Dermochelys coriacea (Vandelli), Environmental Protection Agency, Brisbane, Australia, 2009.

[26] M. Flint, J. M. Morton, C. J. Limpus, J. C. Patterson-Kane, P. J. Murray, and P. C. Mills, "Development and application of biochemical and haematological reference intervals to identify unhealthy green sea turtles (Chelonia mydas)," The Veterinary Journal, vol. 185, no. 3, pp. 299-304, 2010.

[27] J. J. Meager and C. J. Limpus, "Mortality of inshore marine mammals in eastern Australia is predicted by freshwater discharge and air temperature," PLoS ONE, vol. 9, no. 4, Article ID e94849, 2014.

[28] M. Flint, J. C. Patterson-Kane, C. J. Limpus, T. M. Work, D. Blair, and P. C. Mills, "Postmortem diagnostic investigation of disease in free-ranging marine turtle populations: a review of common pathologic findings and protocols," Journal of 
Veterinary Diagnostic Investigation, vol. 21, no. 6, pp. 733-759, 2009.

[29] A. A. Aguirre and P. L. Lutz, "Marine turtles as sentinels of ecosystem health: is fibropapillomatosis an indicator?" EcoHealth, vol. 1, no. 3, pp. 275-283, 2004.

[30] S. P. Epperly, J. Braun, A. J. Chester et al., "Beach strandings as an indicator of at-sea mortality of sea turtles," Bulletin of Marine Science, vol. 59, no. 2, pp. 289-297, 1996. 

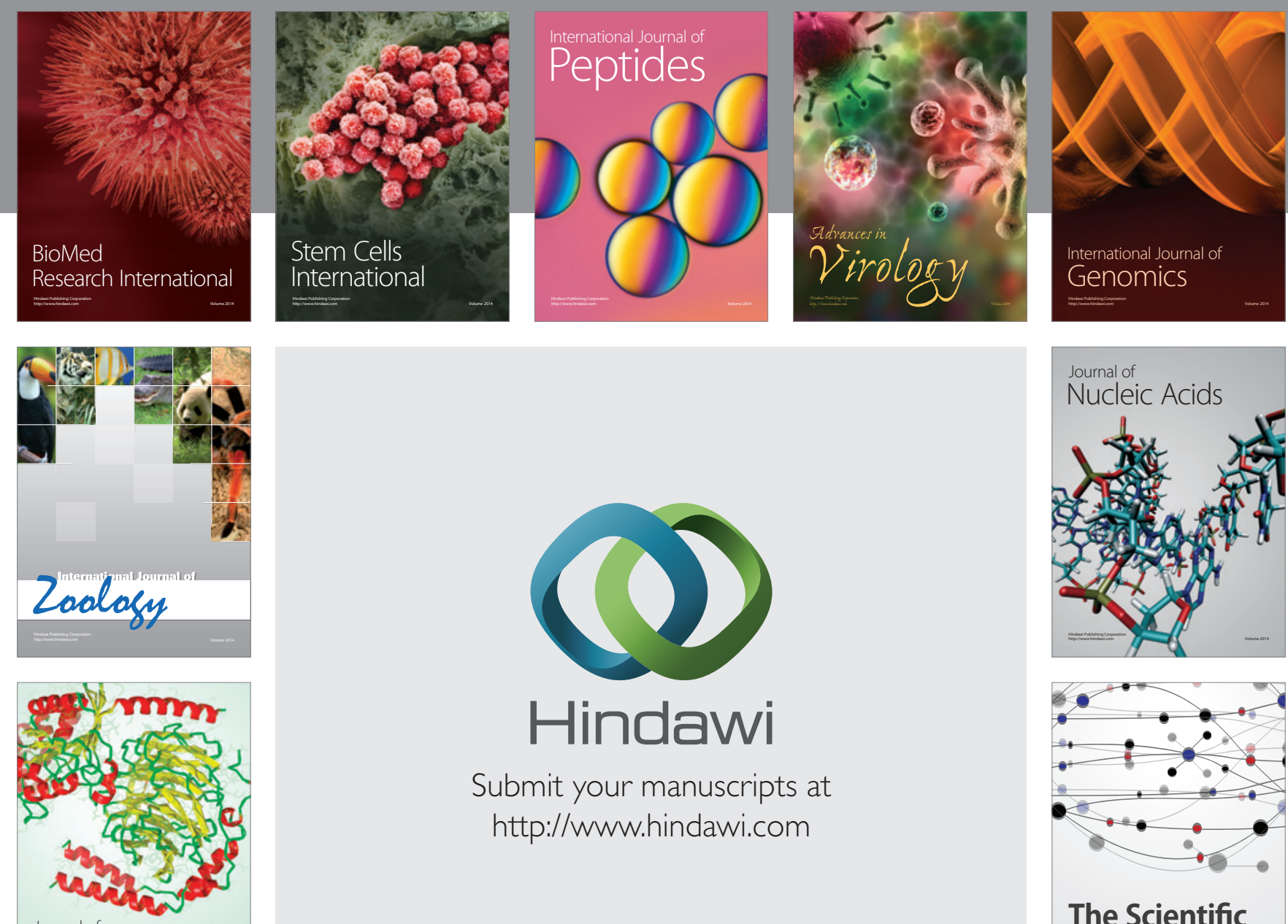

Submit your manuscripts at

http://www.hindawi.com

Journal of
Signal Transduction
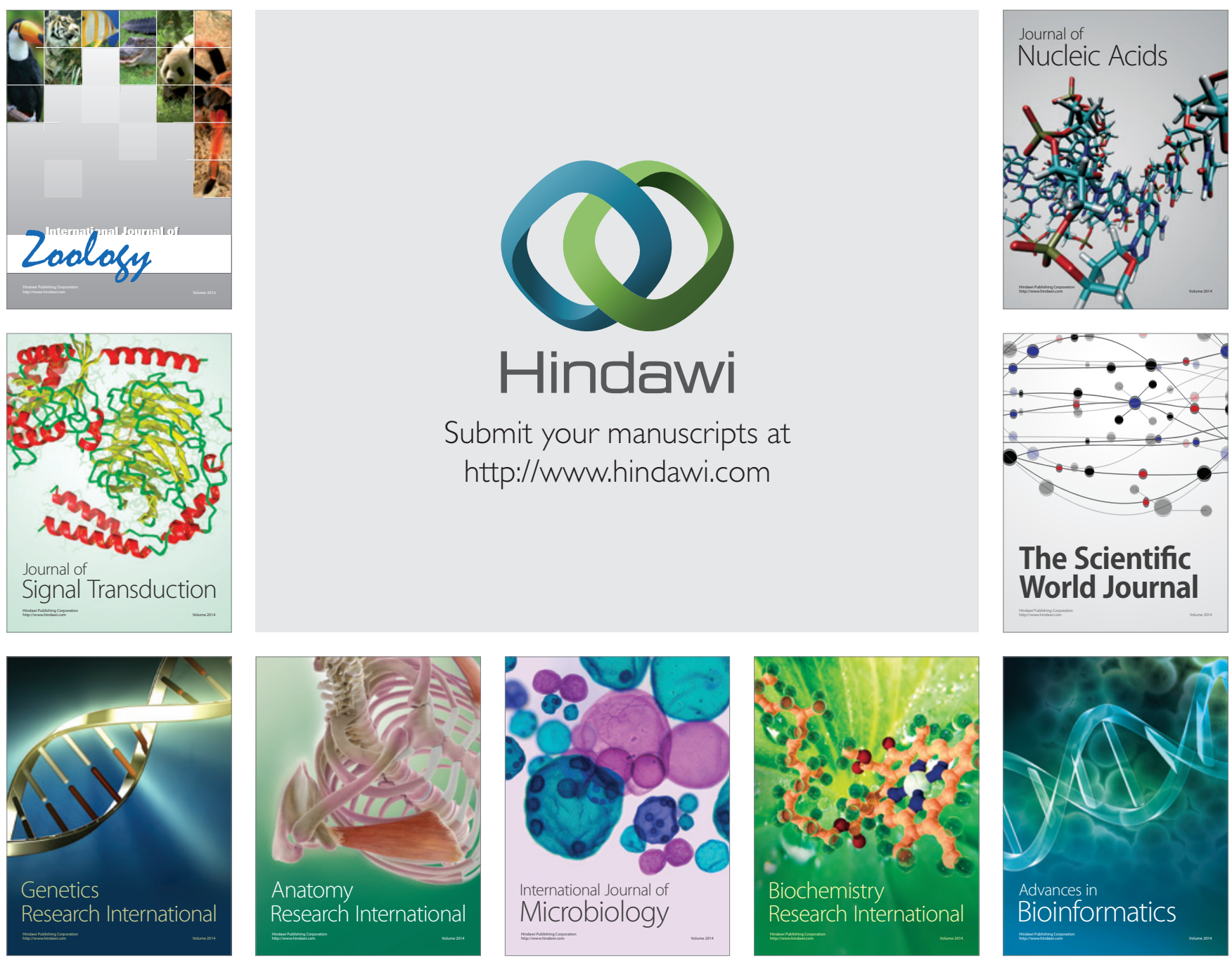

The Scientific World Journal
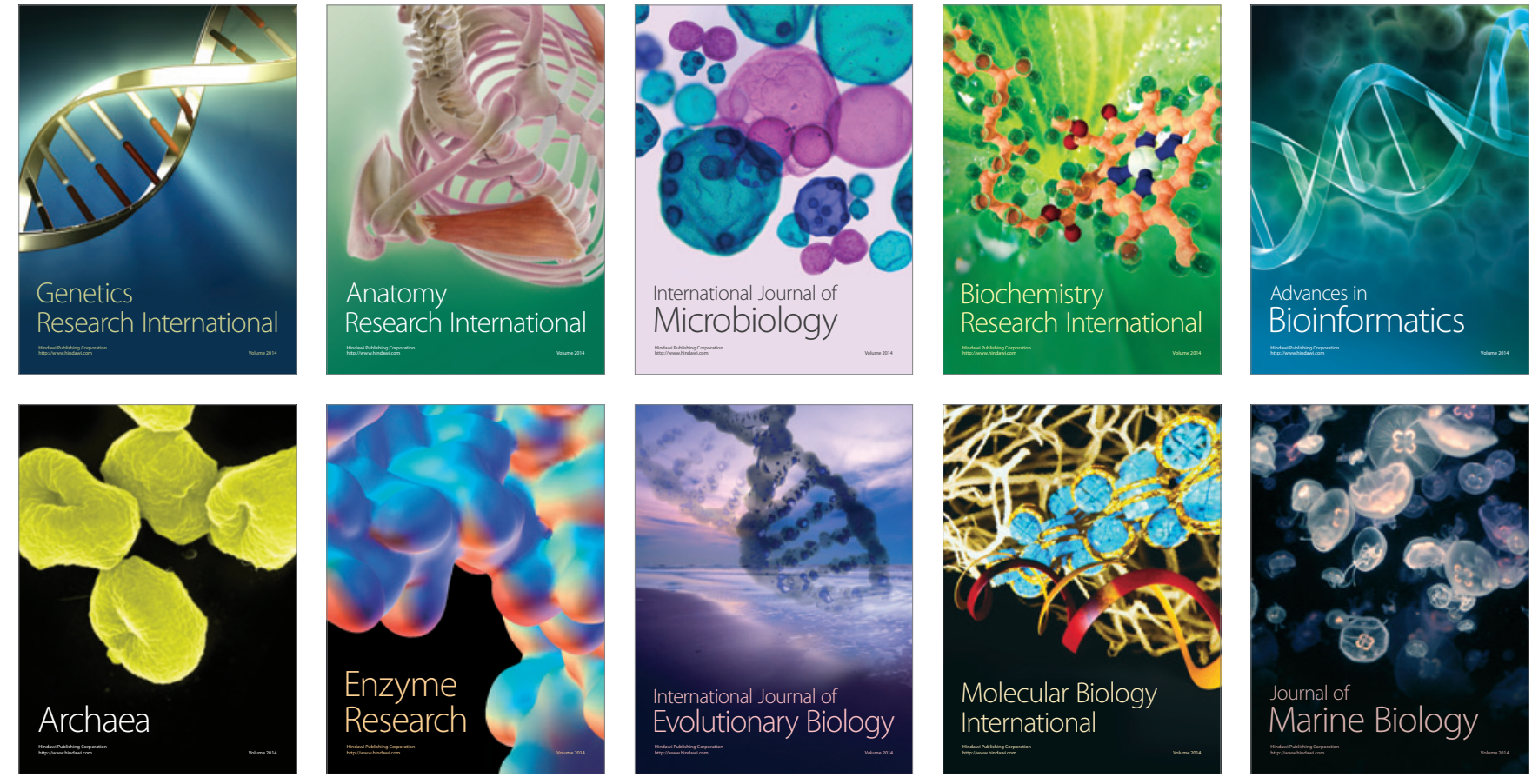